\title{
Hepatitis E seroprevalence and risk factors in humans and pig in Ghana
}

\author{
Husein Bagulo ${ }^{1,2,4^{*}}$, Ayodele O. Majekodunmi ${ }^{1,2,4}$, Susan C. Welburn ${ }^{1,4}$ and Langbong Bimi ${ }^{3}$
}

\begin{abstract}
Background: Although Hepatitis E virus (HEV) infection has significant negative impact on the health and wellbeing of underprivileged populations, the burden of HEV in Ghana is still unclear, despite widespread water, sanitation, and hygiene (WASH) related conditions that predispose people to the risk of infection.

Methods: A cross-sectional study was conducted to explore rates of HEV seroprevalence and HEV prevalence, as well as risk factors in humans and domestic pigs in Ghana. These were determined using ELISAs manufactured by Wantai Beijing Biopharmaceuticals, China. The study involved 1365 community members, 105 pig farmers and 474 domestic pigs from four administrative regions of Ghana.

Results: Results showed overall seroprevalence and prevalence of $12.4 \%$ and $0.7 \%$ in community members and $15.2 \%$ and $2.9 \%$ in pig farmers respectively. There was no significant difference in the seroprevalence between the two groups $(Z=0.851 ; p=0.3953)$. However, the prevalence in pig farmers was significantly higher than in community members $(Z=2.412 ; p=0.016)$. Age $(O R=1.369, C l=1.243-1.508 ; p=0.0000)$, gender $(O R=1.419, C l=1.101$ $-1.991 ; p=0.043)$, and the region of residence $(O R=1.569, C l=1.348-1.827 ; p=0.0000)$ were significant risk factors for HEV seroprevalence in a multivariate regression model.

In pigs, overall seroprevalence and prevalence of $62.4 \%$ and $5.5 \%$ were recorded respectively. A significant difference in seroprevalence was found between confined (6.7\%) and free-range pigs (88.3\%), $(Z=7.492 ; p<0.00001)$ in the Volta Region. Multivariate logistic regression showed a significant association between seroprevalence and husbandry $(\mathrm{OR}=7.051, \mathrm{Cl}=3.558-13.972 ; \mathrm{p}=0.0000)$ and region $(\mathrm{OR}=4.602, \mathrm{Cl}=2.300-9.205 ; \mathrm{p}=0.0000)$ in pigs in the Volta and Greater Accra Region.
\end{abstract}

Conclusion: From this study, HEV is endemic in Ghana with high seroprevalence in humans and pig populations. This underscores the need for awareness creation and action for prevention and control.

Keywords: Hepatitis E, Pigs, Water, Sanitation, Hygiene

\section{Introduction}

Viral hepatitis present a major threat to public health security, causing severe morbidities and high mortalities through acute and chronic infections [1]. Hepatitis E virus (HEV) infection is recognised as one of the primary

\footnotetext{
*Correspondence: hbagulo@ug.edu.gh

${ }^{1}$ Zhejiang University - University of Edinburgh Institute, Zhejiang

University International Campus, 718 East Haizhou Rd, Haining, Zhejiang

314400, People's Republic of China

Full list of author information is available at the end of the article
}

causes of acute viral hepatitis in humans worldwide [2]. It is a serious public health disease in many developing countries, especially in regions of high faecal contamination of drinking water supplies and poor sanitation [3]. As a neglected tropical disease related to water, sanitation, and hygiene (WASH), HEV infection has a huge burden on many underprivileged populations in developing countries but has gained insufficient attention in terms of control interventions, research, and treatment options $[4,5]$. 
In Ghana, environmental risk factors for transmission of the infection to humans are ubiquitous: sanitation coverage is low at $15 \%$ with a $19 \%$ open defecation rate [6]. Also, there is widespread faecal contamination of drinking water [7]. Furthermore, domestic pigs, which are the primary host of the HEV are allowed to roam free in major pig production communities in Ghana; thus, serving as agents of environmental contamination by shedding the virus in faeces and urine.

The burden of this zoonotic infection is not well known in Ghana, although there have been considerable studies on the infection in the country. Results from some localised serosurveys in various populations groups in Ghana such as pig handlers or persons with contact with pigs [8-10], blood donors [11, 12], and pregnant women [13, 14] highlight high HEV seroprevalence but the prevalence (i.e. current infections) and risk of transmission to the general public are not yet known. While the research available provides some insight into the problem of HEV infection in Ghana, some knowledge gaps remain: Most of the previous studies featured small study areas and sample sizes and specific population groups rather than the general public. Also, very young children (age 1-5 years) were not involved.

To fill these gaps, a large cross-sectional study was conducted between October 2019 and October 2020 to investigate the contribution of zoonotic and WASHrelated transmission routes to the burden of HEV infection in humans and domestic pigs in the South East of Ghana. HEV seroprevalence, prevalence and associated risk factors are presented in this paper. These results enable us to better gauge the regional distribution and drivers of HEV infection and the national burden of the disease, which are crucial for a better understanding of the epidemiology of the disease, improving awareness, and evidence-based decision making by policymakers in Ghana.

\section{Materials and methods Sampling frame and study sites}

A pre-survey was carried out between July and September 2019 in all selected districts to confirm and sample communities with the desired characteristics. The district league tables of UNICEF and WaterAid Ghana were used as a guide to identify open defaecation and open defaecation-free communities. Contacts with prospective participants and local authorities were also made during the pre-survey.

The sampling frame included four [4] regions of Ghana, namely, the Greater Accra Region, the Volta Region, the Eastern Region, and the Central Region. In each region, two [2] districts were randomly selected and, in each district, two [2] communities were purposely selected targeting the desired community types giving a total of sixteen [16] communities.

Sanitation records from the Community-Led Total Sanitation programme [15] provided the open defaecation status of the study communities. A pre-survey provided data on other community characteristics.

The selected communities were a combination of "presence or absence of open defaecation (OD)" and "presence or absence of free-range pigs (PIG)" to explore the contribution of pigs and sanitation to the transmission of HEV. Thus, there were four categories of study communities: (1) Absence of both pigs and open defaecation (PIG- OD-), (2) Presence of both pigs and open defaecation $(\mathrm{PIG}+\mathrm{OD}+)$, (3) Absence of pigs and presence of open defaecation (PIG-OD + ), and (4) Presence of pigs and absence of open defaecation (PIG + OD-). The study sites are illustrated in Fig. 1 below.

\section{Study design and sample size estimation}

A cross-sectional cluster survey method was employed for the study. CSurvey software version 2.0 was used to estimate sample sizes of 100 for humans and 160 for pigs per cluster at a desired level of precision of $0.05 \%$. The estimation was done using HEV seroprevalence values of $37 \%$ and $85 \%$ for humans and pigs respectively determined from our previous study in Ghana [16]. Thus, a sample size of 100 people was allocated to each community consisting of 75 community members and 25 pig farmers (3:1 ratio). However, in communities without pig farmers only community members were sampled; thus, 100 community members. For pigs, since only two of the four communities sampled from each region included pigs, a sample size of 160 pigs was assigned to each community. Extensive sensitization exercise was carried during the pre-survey period and a day before sampling in the communities to ensure maximum participation in the study. However, in some communities, the desired sample sizes could not be achieved due to religious beliefs held by participants against blood sampling.

Table 1 shows the region, district, community, community status, and the number of research participants and pigs sampled from each study community.

\section{Sampling technique}

A purposive sampling technique was used to sample the study participants. Every male or female aged 1 and above and a resident of the study community was eligible to participate in the study. In each study community, pig farmers and community members were sampled representing occupationally exposed and unexposed populations respectively, while free-range and confined pigs were sampled. To ensure that as many as possible pig farmers in the study communities participated in the 


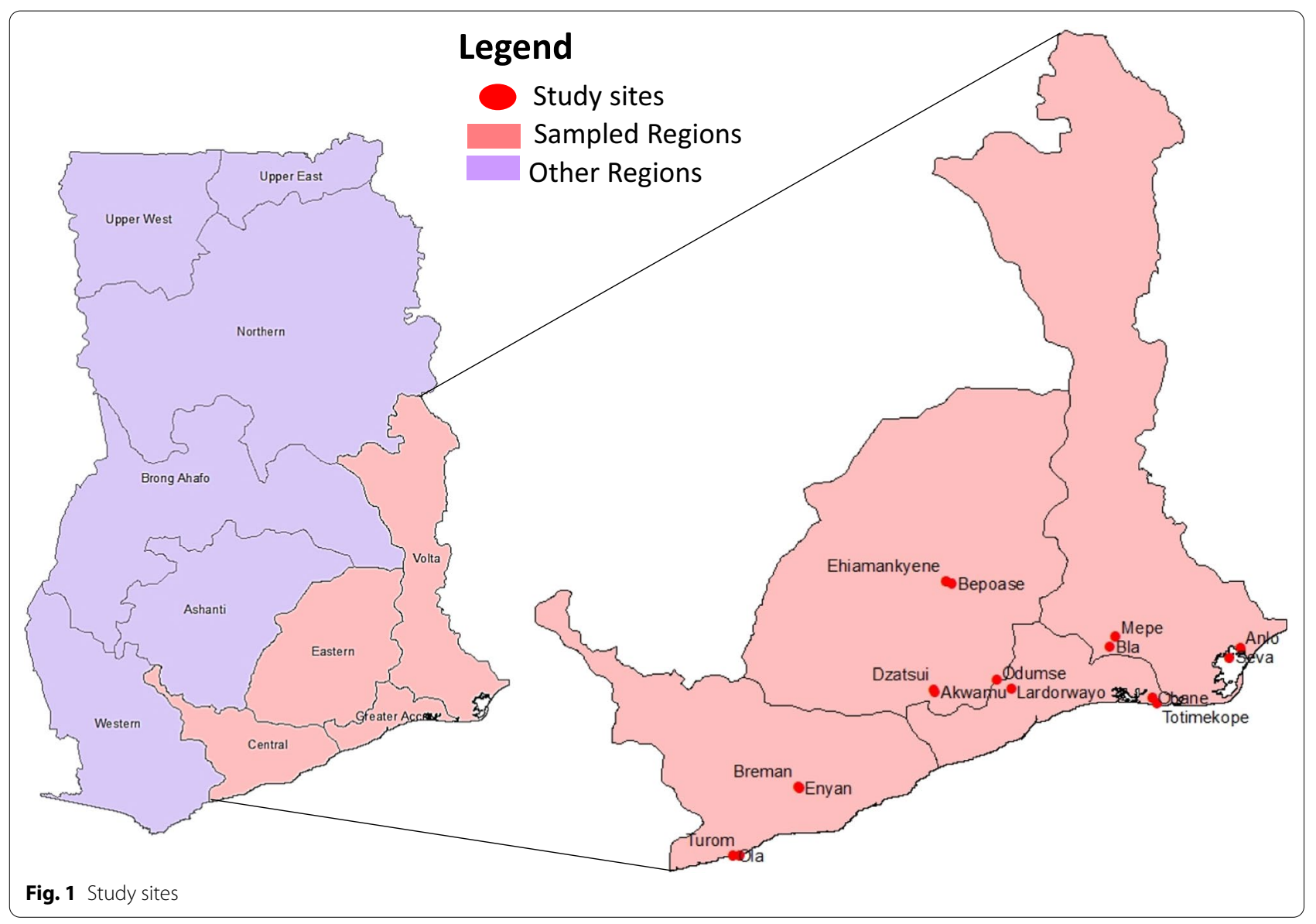

Table 1 Number of participants and pigs sampled

\begin{tabular}{|c|c|c|c|c|c|c|c|}
\hline Region & District & Community & Community Status & $\begin{array}{l}\text { Community } \\
\text { Members }\end{array}$ & Pig Farmers & Total Samples & Pigs \\
\hline \multirow[t]{4}{*}{ Accra } & Ada East & Totimehkope & $+\mathrm{OD}$ PIG- & 99 & 6 & 105 & 30 \\
\hline & & Obane & $+\mathrm{ODPIG}+$ & 43 & 15 & 58 & 89 \\
\hline & Shai Osudoku & Odumase & $+\mathrm{ODPIG}+$ & 91 & 3 & 94 & 83 \\
\hline & & Lardor Wayo & $-\mathrm{OD}$ PIG + & 80 & 4 & 84 & - \\
\hline \multirow[t]{4}{*}{ Central } & Ajumako & Turom & + OD PIG+ & 90 & 4 & 94 & - \\
\hline & & Ola Estate & $+\mathrm{OD}$ PIG- & 76 & 7 & 83 & 52 \\
\hline & Cape Coast Municipality & Breman Essiam & $\mathrm{OD}-\mathrm{PIG}+$ & 73 & 2 & 75 & 42 \\
\hline & & Denkyira & $-\mathrm{OD}$ PIG- & 104 & 0 & 104 & - \\
\hline \multirow[t]{4}{*}{ Volta } & Keta & Anlo Afiadenyigba & $+\mathrm{ODPIG}+$ & 77 & 27 & 104 & 58 \\
\hline & & Seva & $+\mathrm{ODPIG}+$ & 92 & 12 & 104 & 32 \\
\hline & North Tongu & Bla & $+\mathrm{ODPIG}-$ & 100 & 0 & 100 & - \\
\hline & & Mepe & $-O D$ PIG- & 100 & 0 & 100 & - \\
\hline \multirow[t]{4}{*}{ Eastern } & Nsawam Adoagyire & Akwamu & $\mathrm{OD}+\mathrm{PIG}-$ & 100 & 0 & 100 & - \\
\hline & & Dzatsui- Newtown & $-\mathrm{OD}$ PIG- & 100 & 0 & 100 & - \\
\hline & Fanteakwa & Bepoase & $-\mathrm{ODPIG}+$ & 81 & 21 & 102 & 63 \\
\hline & & Ehiamankyene & $\mathrm{OD}+\mathrm{PIG}+$ & 59 & 4 & 63 & 25 \\
\hline Total & & & & 1365 & 105 & 1470 & 474 \\
\hline
\end{tabular}


Table 2 HEV markers and test used

\begin{tabular}{llll}
\hline & HEV Marker & Test & Number of Samples Tested \\
\hline Humans & $\lg M$ & RDT & 1470 (All samples) \\
& $\operatorname{lgG}$ & ELISA & 1470 (All Samples) \\
& $\mathrm{Ag}$ & ELISA & 178 (IgM \& IgG Positives) \\
\multirow{3}{*}{ Pigs } & $\mathrm{Ab}$ & ELISA & 474 (All Samples) \\
& $\mathrm{Ag}$ & ELISA & 296 (Ab Positives) \\
\hline
\end{tabular}

study, engagement with their local association and snowballing were used to recruit them.

\section{Data and sample collection and Processing}

Blood samples (3-5 ml) from human participants and pigs were collected by trained phlebotomists and veterinarians respectively and allowed to clot. The samples were then centrifuged at $3000 \mathrm{rpm}$ for $5 \mathrm{~min}$ for serum separation. The resulting serum samples were then transferred into labelled cryo-tubes and stored at $-20{ }^{\circ} \mathrm{C}$ at the serology laboratory of the Noguchi Memorial Institute for Medical Research, University of Ghana.

Structured questionnaires containing closed and open ended-questions were administered to all consenting participants to obtain data on demographics, attitudes, and practices relating to sanitation water and hygiene, and contact with pigs and pork. This data was used to determine risk factors associated with HEV infection.

\section{Serological methods}

All human serum samples were tested for anti-HEV antibodies Immunoglobulin G (IgG) (sensitivity 99.08\%; specificity 99.90\%) and Immunoglobulin (IgM) (sensitivity 97.7\%; specificity 99.28\%) using enzyme-linked immunosorbent assay (ELISA) and rapid immunochromatographic diagnostic kits (RDT) respectively. Pig samples were tested for anti-HEV total antibodies (Ab) using ELISA. Samples testing positive for any of these tests were then tested for HEV antigens (HEV-Ag) using ELISA. The HEV-Ag ELISA is an inexpensive alternative to PCR that can qualitatively detect HEV antigen in serum or plasma samples. The Wantai HEV-Ag ELISA (specificity 99.93\%) detects the open reading frame 2 (ORF2) capsid antigen of HEV. All the diagnostic test kits were manufactured by Wantai Beijing Biopharmaceuticals, China. The assays from Wantai have been proven to have higher sensitivities than other commercial assays without loss of specificity [17-20]. Table 2 show the types of HEV markers and diagnostic test employed.

\section{Data analysis}

The data collected using the structured questionnaires and results of serological tests were entered into
MS-Excel (2016). Statistical analysis was done using the Statistical Package for Social Sciences (SPSS) version 26.0 statistical software (IBM). Descriptive statistics of demographic parameters were computed and results presented as percentages. Binary logistic regression analysis was conducted in both univariate and multivariate models and odds ratios (OR) and their corresponding 95\% confidence intervals (CI) used to determine risk factors associated with HEV infection. The Pearson chi-square $\left(x^{2}\right)$ test was used to test the association between categorical variables while significant difference was tested using a $\mathrm{Z}$ test. Significance was accepted at the level of $P<0.05$.

\section{Results}

\section{Demographic characteristics of study participants}

Overall, 1470 participants were sampled from sixteen communities in four regions of Ghana. Of the total number of participants, 1365 (92.9\%) were community members and 105 (7.1\%) were pig farmers. A total of 877 of the participants were females (59.7\%) and 593 (40.3\%) males. The ages of the participants range from 1 to 92 years, with a mean age $\pm S D$ of $40.41 \pm 22.24$ years, a median of 40 years, and a mode of 60 years.

\section{HEV in humans}

The overall seroprevalence indicating past or present exposure to HEV in humans was $12.6 \%$.

This was higher in pig farmers (15.2\%) than in community members (12.4\%). However, the difference was not statistically significant $(Z=0.8506 ; p=0.3953)$.

HEV IgG only seroprevalence in this study was $11.9 \%$. HEV IgG seroprevalence was higher in males (13.3\%) than females $(11.3 \%)$, Table 3 , but the difference was not statistically significant; $Z=1.173 ; p=0.242$. The HEV IgG seroprevalence was also not significantly different between community members (11.6\%) and pig farmers (15.2\%); $(Z=1.095 ; p=0.2757)$. HEV IgG seroprevalence increased quite consistently and significantly with increasing age; $x^{2}=67.021 ; p=0.000$ as shown in Fig. 2. The HEV IgG seroprevalence was lowest $(0 \%)$ in the $1-4$ years age group and highest $(20.8 \%)$ in the $40-49$ years age group. Amongst the four regions, the HEV IgG seroprevalence ranged from $6.0 \%$ in the Eastern Region to $20.2 \%$ in the Central Region. It was significantly associated with region, $x^{2}=42.272$; $p<0.00001$. The HEV IgG seroprevalence in the Central Region (20.2\%) and the Greater Accra Region (14.7\%) were significantly higher than those in the Eastern Region (6.0\%) and the Volta Region (8.3\%). The regional distribution of HEV IgG seroprevalence in humans is shown in Fig. 3. Similarly, HEV IgG Seroprevalence significantly increased with the level of education as with age, with the lowest infections in persons with nursery 
Table 3 Demographics and HEV IgG seroprevalence

\begin{tabular}{|c|c|c|c|c|}
\hline Demographic Variables & $\mathbf{N}$ & Percentage (Mean) & HEV IgG seroprevalence (\%) & $P$ Value \\
\hline \multicolumn{5}{|l|}{ Gender } \\
\hline Male & 593 & $40.3 \%$ & 13.3 & 0.242 \\
\hline Female & 877 & $59.7 \%$ & 11.3 & \\
\hline \multicolumn{5}{|l|}{ Age group } \\
\hline $1-4$ & 44 & $3.0 \%(2.9)$ & 0 & \\
\hline $5-9$ & 91 & $6.2 \%(7.0)$ & 2.2 & \\
\hline $10-14$ & 87 & $5.9 \%(12.3)$ & 3.4 & \\
\hline $15-19$ & 110 & $7.5 \%(17.1)$ & 3.6 & \\
\hline $20-29$ & 196 & $13.3 \%(24.4)$ & 5.6 & 0.000 \\
\hline $30-39$ & 199 & $13.5 \%(34.8)$ & 10.1 & \\
\hline $40-49$ & 178 & $12.1 \%(44.3)$ & 20.8 & \\
\hline $50-59$ & 209 & $14.2 \%(54.1)$ & 18.7 & \\
\hline $60+$ & 356 & $24.2 \%(69.7)$ & 17.4 & \\
\hline \multicolumn{5}{|l|}{ Region } \\
\hline Accra & 341 & $23.2 \%$ & 14.7 & \\
\hline Eastern & 365 & $24.8 \%$ & 6.0 & \\
\hline Volta & 408 & $27.8 \%$ & 8.3 & 0.000 \\
\hline Central & 356 & $24.2 \%$ & 20.2 & \\
\hline \multicolumn{5}{|l|}{ Educational level } \\
\hline None & 347 & $23.6 \%$ & 16.7 & \\
\hline Nursery & 59 & $4.0 \%$ & 1.7 & \\
\hline Primary & 346 & $23.5 \%$ & 11.6 & \\
\hline JHS & 552 & $37.6 \%$ & 10.5 & 0.008 \\
\hline SHS & 120 & $8.2 \%$ & 10.8 & \\
\hline Tertiary & 46 & $3.1 \%$ & 17.4 & \\
\hline \multicolumn{5}{|l|}{ Population group } \\
\hline Community Member & 1365 & $92.9 \%$ & 11.9 & 0.308 \\
\hline Pig Farmer & 105 & $7.1 \%$ & 15.2 & \\
\hline \multicolumn{5}{|l|}{ Community type } \\
\hline$-\mathrm{OD}$ PIG- & 304 & $20.7 \%$ & 13.8 & \\
\hline$-\mathrm{OD} \mathrm{PIG}+$ & 261 & $17.8 \%$ & 11.9 & 0.214 \\
\hline$+O D$ PIG- & 388 & $26.4 \%$ & 13.9 & \\
\hline$+\mathrm{ODPIG}+$ & 517 & $35.2 \%$ & 9.9 & \\
\hline
\end{tabular}

education $(1.7 \%)$ and the highest in persons with tertiary education $(17.4 \%),\left(x^{2}=15.747 ; p=0.008\right)$. HEV IgG seroprevalence amongst community types did not differ significantly; $x^{2}=4.485, p=0.214$; ranging from $9.9 \%$ in + OD PIG + communities to $13.9 \%$ in -OD PIG + communities.

HEV IgM only seroprevalence was $0.5 \%$. Only community members tested positive for this antibody.

The prevalence (HEV-Ag) was $0.8 \%$; It was significantly different in pig farmers and community members ( $2.9 \%$ vs $0.7 \% ; Z=2.412 ; \mathrm{p}=0.016)$. The seroprevalence and prevalence results are shown in Table 4.

\section{Demographic risk factors associated with HEV IgG seroprevalence in humans}

A univariate logistic regression model showed that age group, level of education, and region were significant demographic risk factors for HEV IgG seropositivity; $P=0.0000, \mathrm{P}=0.0009$, and $P=0.0000$ respectively, Table 5. There was 1.4 times more risk of being seropositive for HEV for each age group from the lowest age group to the highest (OR 1.365; 95\% CI 1.252-1.488). HEV IgG seroprevalence increased from $0.0 \%$ in the $1-4$ years age group to $17.4 \%$ in the $60+$ years age group. Similarly, there was 1.2 times more risk of being HEV seropositive associated with each level of education from the lowest to the highest. HEV IgG seroprevalence 


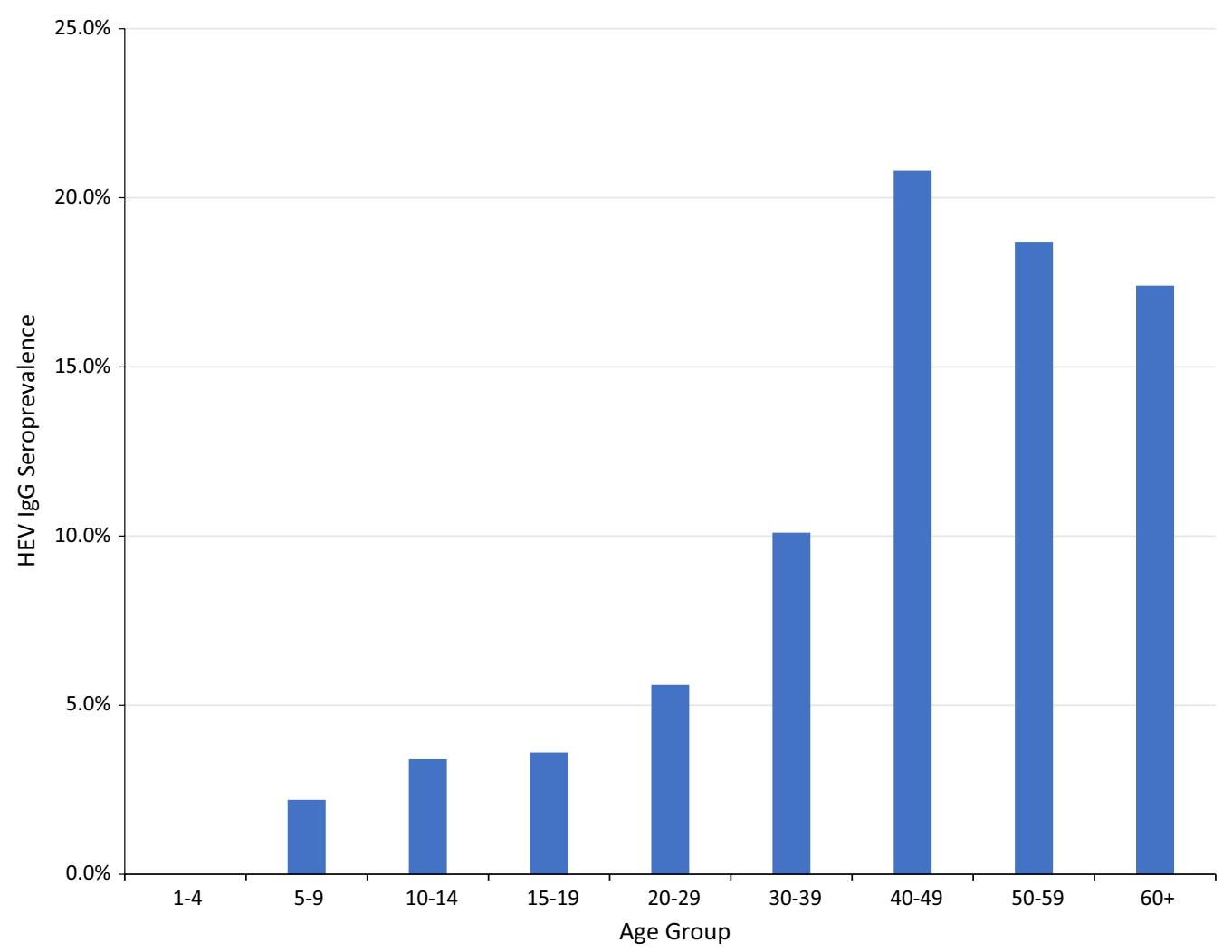

Fig. 2 HEV IgG seroprevalence amongst age groups

increased from $1.7 \%$ in persons with nursery education to $17.4 \%$ in persons with tertiary education. A 1.6 times more risk of HEV IgG seropositivity was associated with each region in this order; Eastern $<$ Volta $<$ Accra $<$ Central. The risk factors for HEV IgG seroprevalence in humans are shown in Table 5.

In a multivariate logistic regression model age group $(P=0.0000)$ and region $(P=0.0082)$ remained significant predictor of HEV IgG seropositivity along with gender $(P=0.0433)$. Males were 1.4 times more likely to be seropositive for HEV than females (OR 1.418; 95\% CI 1.011-1.991). However, the HEV IgG seroprevalence in males and females was not significantly different (13.3\% vs $11.3 \% ; Z=1.173, P=0.242$ ). Age group was significantly associated with HEV IgG seropositivity; the odds of HEV IgG seropositivity increased from 1.4 times in the $1-4$ years age group to 16.9 times in the $60+$ years age group. The region of residence as a demographic risk factor significantly predicted HEV IgG seropositivity with the highest risk in Central Region (OR 6.1), followed by the Greater Accra Region (OR 3.9) and the Volta Region (OR 2.5) with the lowest in Eastern Region (OR 1.7). Other demographic factors such as level of education, type of community, and population group did not show significant association with HEV IgG seroprevalence.

\section{HEV in pigs}

A total of 474 pigs were sampled: 202 from the Greater Accra Region, 90 from Volta Region, 94 from Central Region, and 88 from Eastern Region. Free-range pigs were sampled from all four regions, whereas confined pigs were only available for sampling in the Greater Accra and Volta Regions. The sampled regions, number of pigs, and HEV-Ab seroprevalence as well as their $p$ values are displayed in Table 6.

An overall HEV-Ab seroprevalence of $62.4 \%$ was recorded in the pigs. HEV-Ab seroprevalences amongst the free-range pigs from the various regions were significantly different; $x^{2}=113.4 ; p=0.000$. A significantly higher HEV-Ab seroprevalence was demonstrated in pigs in the Greater Accra Region (85.7\%) and the Volta Region $(88.3 \%)$ than in the Eastern Region (18.2\%) and the Central Region (51.1\%); $\mathrm{P}<0.00001$ amongst free-range pigs. Also, HEV-Ab seroprevalence in the Central Region was significantly higher than in the Volta Region $(51.1 \%$ vs 18.2\%; $Z=4.643, P<0.00001$ ). Amongst confined pigs, $\mathrm{HEV}-\mathrm{Ab}$ seroprevalence was significantly higher in pigs 


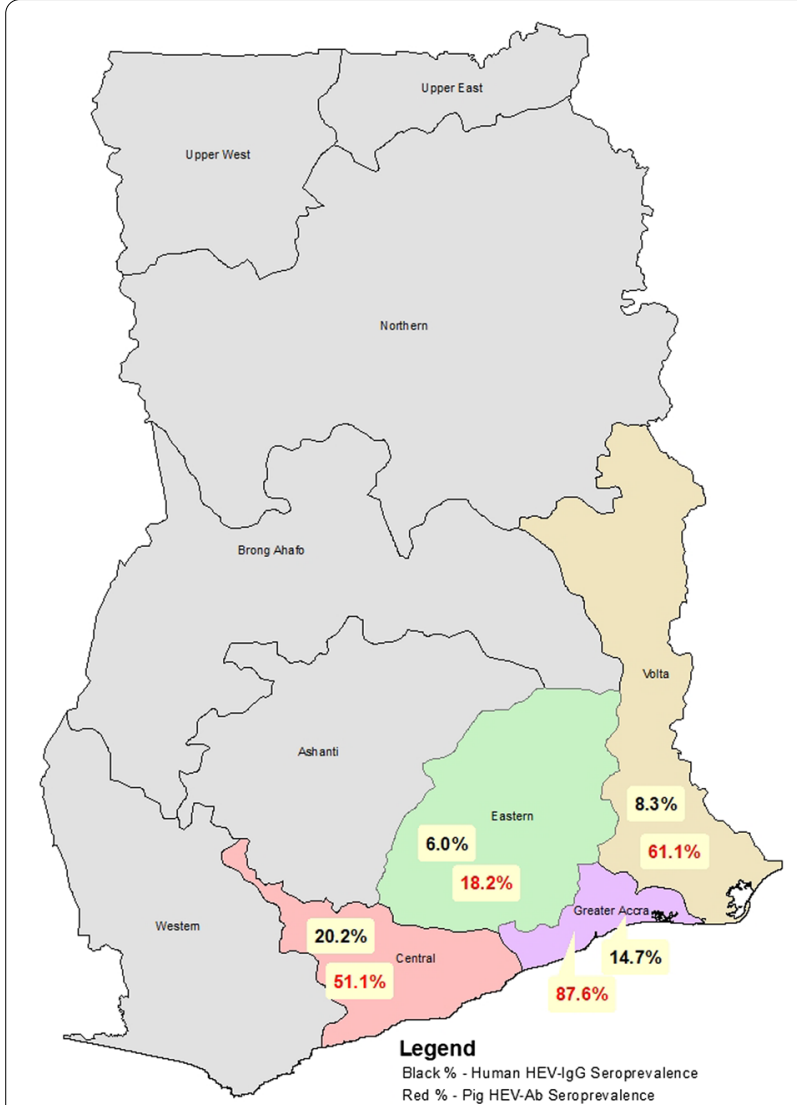

Fig. 3 Regional distribution of HEV-Ab seroprevalence in humans and pigs

in Accra (89.4\%) than in pigs in the Volta Region (6.7\%); $\mathrm{Z}=8.791, p<0.00001$. The regional distribution of HEVAb seroprevalence in pigs is displayed in Fig. 3. Amongst the regions, HEV-Ab seroprevalence between confined and free-range pigs was significantly different only in the Volta Region; $6.7 \%$ vs $88.3 \%$; $\mathrm{Z}=7.492 ; p<0.00001$, Table 6.

An HEV prevalence (HEV-Ag) of $5.5 \%$ was recorded in the pigs. The prevalence amongst both confined and free-range pigs ranged from $1.1 \%$ in the Eastern Region to $9.6 \%$ in the Central Region. Prevalence between confined $(8.7 \%)$ and free-range (3.1\%) pigs in Accra was not significantly different; $(Z=1.6806, P=0.09296)$.

\section{Risk factors of HEV-Ab seroprevalence in pigs}

HEV-Ab seroprevalence showed a significant association with husbandry and region for pigs in Accra and Volta region in both univariate and multivariate logistic regression models, Table 7. A significantly higher HEV-Ab seroprevalence was found in free-range pigs compared with confined pigs $(86.7 \%$ vs $70.9 \%) ; Z=3.333 ; p=0.0086$. The odds of HEV-Ab seroprevalence amongst free-range pigs was seven-fold higher than in confined pigs in the multivariate model $(p=0.0000)$. Also, the odds of HEV-Ab seroprevalence was about 5times higher for pigs in Accra than pigs in the Volta Region $(p=0.0000)$.

Husbandry and region, however, were not significant predictors of HEV-Ag prevalence in both univariate and multivariate logistic regression models. Table 7 shows the univariate and multivariate logistic regression of risk factors associated with HEV seroprevalence and prevalence in pigs.

\section{Discussion}

\section{HEV in humans}

In this study, seroprevalence, prevalence and risk factors for human and pig infection with HEV were explored to determine the burden of the disease and the contribution of zoonotic and WASH-related transmission routes in Ghana.

The results show an overall seroprevalence of $12.6 \%$ and prevalence of $0.8 \%$ in humans in Ghana. This prevalence indicates endemic circulation of HEV in the study communities and Ghana at large which warrants action. There was no significant difference in overall seroprevalence between pig farmers and the general public in this study. The overall seroprevalence of $12.4 \%$ in community members in this study was lower than the $13.4 \%$ previously reported in blood donors by Meldal et al., [12] in Ghana. The difference in seroprevalence between the two studies could be because this study covered a much broader population, age range, and regions in Ghana than the other. The effect of differences in time and diagnostics assays used could also be significant factors. Also, the overall seroprevalence in community members in this study was much lower than the seroprevalence of $47.9 \%$ recorded in healthy people in Nigeria [21]. The difference in seroprevalence between these two studies may be reflective of variation in sample size and age range of research participants. Moreover, differences in sanitation practices, socioeconomic status, and level of exposure of participants to risk factors of HEV infection could be possible reasons. In Asia, an HEV seroprevalence of $11 \%$ each was reported in healthy people in Taiwan [22] and Mongolia [23] which are very close to the seroprevalence in this study.

HEV seroprevalence of $15.2 \%$ (IgG) and 0\% (IgM) was recorded for pig farmers in this study compared with $0 \% \mathrm{HEV}$ IgG and the 38.1\% HEV IgM seroprevalence reported by Adjei, Aviyase [24] in pig handlers in Ghana. It is unclear why Adjei did not record any HEV IgG but a high HEV IgM. Exposure of an HEV naïve population to infections for the first time could be the reason. As most of the participants had been working on the pig farms for less than a year and HEV infection was significantly 
Table 4 Seroprevalence and prevalence in community members and pig farmers

\begin{tabular}{|c|c|c|c|c|}
\hline HEV test & $\begin{array}{l}\text { Community member } \\
(n=1365)\end{array}$ & $\begin{array}{l}\text { Pig FARMER } \\
(n=105)\end{array}$ & $\begin{array}{l}\text { Total } \\
(n=1470)\end{array}$ & Total \\
\hline \multicolumn{5}{|l|}{ Antibody } \\
\hline IgM only & $7(0.51 \%)$ & $0(0 \%)$ & 7 & $0.5 \%$ \\
\hline IgG only & $159(11.6 \%)$ & $16(15.2 \%)$ & 175 & $11.9 \%$ \\
\hline $\lg M+\lg G$ & $3(0.22 \%)$ & $0(0 \%)$ & 3 & $0.2 \%$ \\
\hline Overall Seroprevalence & $12.4 \%$ & $15.2 \%$ & 185 & $12.6 \%$ \\
\hline \multicolumn{5}{|l|}{ Antigen } \\
\hline HEV Antigen & (9) $\mathbf{0 . 7 \%}$ & (3) $2.9 \%$ & 12 & $0.8 \%$ \\
\hline
\end{tabular}

Table 5 Logistic Regression of Demographic Risk factors for HEV IgG Infection in Humans

\begin{tabular}{|c|c|c|c|c|c|c|c|c|}
\hline \multirow[t]{2}{*}{ Variable } & \multirow[t]{2}{*}{ Coeff } & \multirow[t]{2}{*}{ StdErr } & \multirow[t]{2}{*}{ PValue } & \multirow[t]{2}{*}{ OR } & \multicolumn{2}{|c|}{$(95 \% \mathrm{Cl})$} & \multicolumn{2}{|c|}{ Overall Model Fit } \\
\hline & & & & & Low & High & $x^{2}$ & $P$ \\
\hline \multicolumn{9}{|c|}{ Univariate logistic regression } \\
\hline Gender & 0.1888 & 0.1612 & 0.2415 & 1.2078 & 0.8806 & 1.6567 & 1.3635 & 0.2429 \\
\hline Age Group & 0.3110 & 0.0440 & 0.0000 & 1.3648 & 1.2521 & 1.4876 & 61.5476 & 0.0000 \\
\hline Level of education & 0.1648 & 0.0495 & 0.0009 & 1.1792 & 1.0701 & 1.2994 & 10.9089 & 0.0010 \\
\hline Category & 0.2889 & 0.2841 & 0.3092 & 1.3350 & 0.7649 & 2.3300 & 0.9773 & 0.3229 \\
\hline Community type & -0.1038 & 0.0693 & 0.1343 & 0.9014 & 0.7869 & 1.0326 & 2.2273 & 0.1356 \\
\hline Region & 0.4786 & 0.0768 & 0.0000 & 1.6137 & 1.3883 & 1.8758 & 41.5532 & 0.0000 \\
\hline \multicolumn{9}{|c|}{ Multivariate logistic regression } \\
\hline Gender & 0.3496 & 0.1730 & 0.0433 & 1.4185 & 1.0106 & 1.9912 & & \\
\hline Age Group & 0.3144 & 0.0493 & 0.0000 & 1.3694 & 1.2433 & 1.5083 & & \\
\hline Level of education & 0.0454 & 0.0570 & 0.4254 & 1.0465 & 0.9359 & 1.1702 & 104.166 & 0.0000 \\
\hline Category & 0.2857 & 0.2992 & 0.3397 & 1.3307 & 0.7403 & 2.3919 & & \\
\hline Community type & -0.0361 & 0.0733 & 0.6225 & 0.9645 & 0.8354 & 1.1136 & & \\
\hline Region & 0.4506 & 0.0777 & 0.0000 & 1.5693 & 1.3477 & 1.8272 & & \\
\hline
\end{tabular}

Table 6 Seroprevalence and prevalence in pigs

\begin{tabular}{|c|c|c|c|c|c|c|}
\hline Region & Husbandry & Number & Seroprevalence & $P$ Value & Prevalence & $P$ Value \\
\hline \multirow[t]{2}{*}{ Accra } & Confined & 104 & (93) 89.4\% & 0.424 & (9) $8.7 \%$ & 0.093 \\
\hline & Free-Range & 98 & (84) $85.7 \%$ & & (3) $3.1 \%$ & \\
\hline \multirow[t]{2}{*}{ Volta } & Confined & 30 & (2) $6.7 \%$ & $<0.00001$ & 0 & 0.297 \\
\hline & Free-Range & 60 & (53) $88.3 \%$ & & (4) $6.7 \%$ & \\
\hline \multirow[t]{2}{*}{ Central } & Confined & 0 & 0 & - & - & \\
\hline & Free-Range & 94 & (48) $51.1 \%$ & & (9) $9.6 \%$ & - \\
\hline \multirow[t]{2}{*}{ Eastern } & Confined & 0 & 0 & - & - & \\
\hline & Free-range & 88 & (16) $18.2 \%$ & & (1) $1.1 \%$ & - \\
\hline Total & - & 474 & (296) 62.4\% & & (26) $5.5 \%$ & \\
\hline
\end{tabular}

associated with persons who had been working on the farm for less than one year.

Compared with other serosurveys in Africa, HEV seroprevalence in pig farmers in this study was considerably lower than the $58.3 \%$ and $76 \%$ recorded in animal handlers in Nigeria and butchers in Burkina Faso respectively $[21,25]$. However, it is comparable with the HEV seroprevalence of $14.1 \%$ reported in pig butchers in Madagascar [26]. The dissimilarities in HEV seroprevalence between occupationally at-risk persons in these studies 
Table 7 Seroprevalence, prevalence and risk factors in pigs

\begin{tabular}{|c|c|c|c|c|c|c|c|c|c|}
\hline \multirow[b]{2}{*}{$\begin{array}{l}\text { Husbandry (Accra } \\
\text { and Volta) }\end{array}$} & \multirow[b]{2}{*}{ HEV Ab } & \multicolumn{4}{|c|}{ Univariate } & \multicolumn{4}{|c|}{ Multivariate } \\
\hline & & OR & Low & High & $P$ value & OR & Low & High & $P$ value \\
\hline Confined & 95 (70.9\%) & & & & & & & & \\
\hline Free-range & 137 (86.7\%) & 2.6782 & 1.4823 & 4.8388 & 0.0011 & 7.0506 & 3.5580 & 13.9716 & 0.0000 \\
\hline \multicolumn{10}{|l|}{ Region } \\
\hline Accra & $177(87.6 \%)$ & & & & & & & & \\
\hline Volta & $55(61.1 \%)$ & 4.5055 & 2.4831 & 8.1750 & 0.0000 & 4.6015 & 2.3003 & 9.2048 & 0.0000 \\
\hline $\begin{array}{l}\text { Husbandry (Accra } \\
\text { and Volta) }\end{array}$ & HEV-Ag & OR & Low & High & $P$ value & OR & Low & High & $P$ value \\
\hline Confined & $9(6.7 \%)$ & & & & & & & & \\
\hline Free-range & $7(4.4 \%)$ & 0.6439 & 0.2332 & 1.7780 & 0.3956 & 0.6663 & 0.2380 & 1.8653 & 0.4396 \\
\hline \multicolumn{10}{|l|}{ Region } \\
\hline Accra & $12(9.0 \%)$ & & & & & & & & \\
\hline Volta & $4(2.5 \%))$ & 1.3579 & 0.4257 & 4.3312 & 0.6052 & 1.2605 & 0.3888 & 4.0867 & 0.6997 \\
\hline
\end{tabular}

may be influenced by the level of exposure of pig farmers to HEV-infected pigs and the level of prevalence of other predisposing factors for HEV transmission.

HEV prevalence in this study was low, as revealed by the overall HEV antigen (HEV-Ag) prevalence of $0.8 \%$ which is supported by the very low recent infection (IgM) of $0.5 \%$. This could be characteristic of a low level of HEV transmission rate.

\section{Demographic risk factors associated with HEV IgG seroprevalence in humans}

Demographic factors were explored in both the univariate and multivariate models to determine risk factors associated with HEV seropositivity. While age group, level of education, and region were associated with HEV seropositivity in the univariate analysis, gender, age group and region were significant predictors of HEV in the multivariate analysis.

Age group significantly predicted HEV IgG seropositivity; the trend of increasing HEV IgG seroprevalence with increasing age in this study is consistent with many reports of HEV studies across the world; in India [27], Kenya [28], CAR [29], Indonesia [30], Taiwan [22], Spain [31], USA [32], and Germany [33]. Since HEV IgG is a marker of exposure and persists for long periods (up to 14 years) [34], the HEV IgG seroprevalence is bound to be higher in older than in younger individuals. Thus, HEV IgG seroprevalence increases with age as a consequence of accumulated infections over time.

While the risk of HEV infection was associated with increasing education this observation is probably influenced by age since higher education level correlates with increasing age. This can be clearly inferred from the similarity in HEV IgG seroprevalence amongst the tertiary and none educated groups. The HEV IgG seroprevalence in persons without education was similar to those who had tertiary education, $17.4 \%$ vs $16.7 \%$. All persons who were positive for HEV IgG seroprevalence in the none educated category were adults aged 20 years and above; education level appears to be a confounder.

Gender was significantly associated with HEV IgG seroprevalence in the multivariate analysis with a higher risk in males than in females. However, the odds ratio was not very high (1.4) and the difference in HEV IgG seroprevalence was not statistically significant, $\mathrm{Z}=1.173$; $p=0.242$.

HEV IgG seroprevalence was significantly associated with the region of residence. The study communities in the Central and Greater Accra regions where HEV IgG seroprevalences were higher were more urban than communities in the Volta and Eastern region where HEV IgG seroprevalences were low. Many studies have found higher HEV IgG seroprevalence in rural than in urban areas $[14,21,35,36]$. In this study, however, it seems to be associated with increasing urbanisation as reported in studies in Gabon [37] and India [38]. Overcrowding in urban areas puts pressure on sanitation and water facilities, creating unhygienic conditions which promote WASH-related HEV transmission. Such conditions are more prevalent in the Greater Accra and Central region than in the Eastern and Volta regions.

\section{$\mathrm{HEV}$ in pigs}

Several serosurveys from many countries across the world have shown high HEV seroprevalence in domestic pigs with increased risk of infection in humans through 
direct contact and consumption of undercooked infected pork products [39]. Unfortunately, studies investigating HEV seroprevalence in domestic pigs and the level of risk of zoonotic transmission from pigs to humans are lacking in Ghana. This study is amongst the few studies jointly investigating HEV in humans and pigs in Ghana.

The high HEV-Ab seroprevalence of $62.4 \%$ demonstrates clearly that HEV is endemic in pig populations in Ghana. The widespread practice of free-range pig husbandry in major pig rearing communities in Ghana exposes pigs to the risk of environmental HEV infections. Also, the practice of introducing free-range breeding stock to intensive farms introduces the disease to these systems.

Only a few HEV seroprevalence studies of pigs are available in Ghana for comparison with the results from this study. The results support the high HEV seroprevalence of $85 \%$ in our previous study in pigs from the Greater Accra and Upper East regions of Ghana. These results altogether enable us to gauge the national HEV seroprevalence as well as the regional distribution of HEV seroprevalence in pigs in Ghana. The HEV-Ab seroprevalence of $62.4 \%$ in this study is lower than the $85 \%$ found in our previous serosurvey [16], and the $77.5 \%$ reported by El-Duah, Dei [40] in the Ashanti region of Ghana. However, the HEV-Ab seroprevalence of $87.6 \%$ in this study and the $80 \%$ in our previous study both in the Greater Accra region are comparable.

When compared with HEV seroprevalence values in pigs from other African countries, our findings were comparable with results in Madagascar [26] and Nigeria [41].

HEV antigen prevalence was relatively low in pigs in Ghana at $5.5 \%$ compared with the $64.2 \%$ seropositive for HEV antibodies. Other studies of HEV prevalence have used PCR on liver samples and so cannot be compared to this study which used antigen ELISA on serum samples. These studies recorded HEV RNA prevalence of $0.9-10.1 \%[26,40,42,43]$.

\section{Conclusion}

This study explored the prevalence and seroprevalence of HEV and risk factors for infection in humans and pigs in Ghana. The results show that HEV infection is endemic in both occupationally at-risk persons and the general population in Ghana. Overall seroprevalence (12.6\%) was much higher than HEV prevalence (0.8\%).

The results also show that HEV is endemic in domestic pig populations which serve as an HEV reservoir. The pervasive free-range pig production system predisposes roaming pigs to environmental HEV. Likewise, scavenging pigs can contaminate the environment by shedding the virus in faeces and urine. It is therefore important that authorities enforce the laws proscribing free-range pig production to prevent this and reduce the risk of HEV infection in pigs. Overall, this study helps define the burden of HEV in human and pig populations in Ghana. Although the HEV prevalence seems to be minimal, the overall seroprevalence is a cause for concern.

Due to low participant responses, the desired sample sizes could not be achieved in some communities. Also, a molecular detection method (RT-PCR) could not be employed in this study due to financial and logistical constraints. These challenges could constitute a limitation of this study. Isolation and characterisation of HEV in humans, animals, and water simultaneously will be key in determining the main transmission route of HEV in Ghana. This notwithstanding, the study brings to light the problem of HEV in Ghana.

\section{Abbreviations \\ Ab: Antibody; Cl: Confidence interval; ELISA: Enzyme-linked immunosorbent assay; HEV: Hepatitis E virus; IgG: Immunoglobulin G; IgM: Immunoglobulin M; OD: Open defaecation; OR: Odds ratio; PCR: Polymerase chain reaction; RDT: Rapid Immunochromatographic diagnostic; RNA: Ribonucleic acid; SPSS: Statistical package for social sciences; WASH: Water, sanitation, and hygiene.}

\section{Acknowledgements}

The authors are grateful to Dr. Linda Amoah of the Noguchi Memorial Institute for Medical Research, University of Ghana for granting us access to use their laboratory for the serological work. We also, acknowledge Mr. Eric Kyei Baffour and Mr. Kwadwo Akyea-Mensah for their assistance in the laboratory work, and Mr. Patrick Tecku for assisting in the fieldwork.

\section{Authors' contributions}

Conceptualisation: HB, AOM, SCW \& LB; Data collection and analysis: HB; Manuscript preparation: $\mathrm{HB}$; Manuscript review and editing: $\mathrm{HB}, \mathrm{AOM}, \mathrm{SCW} \&$ LB. All authors read and approved the final manuscript.

Funding

$A O M \& H B$ received support from the University of Ghana Research Fund UGRF/12/MCG-098/2018-2019.

Availability of data and materials

The datasets used and/or analysed during the current study are available from the corresponding author on reasonable request.

\section{Declarations}

Ethics approval and consent to participate

Ethical approval for the entire study was sought and received from the Ethics Committee of the College of Basic and Applied Sciences, University of Ghana (ECBAS 003/19-20) and the Ghana Health Services Ethical Review Committee (GHS-ERC013/10/19). Informed consent was acquired from all research participants. For minors and illiterate participants, informed consent was obtained from their parents/legal guardians, and pigs were sampled under the informed consent and supervision of their legal owners. All the activities carried out in the research were done following the guidelines and regulations of the Ghana Health Service.

Consent for publication

Not applicable.

Competing interests

The authors declare that they have no competing interests. 


\section{Author details}

'Zhejiang University - University of Edinburgh Institute, Zhejiang University International Campus, 718 East Haizhou Rd, Haining, Zhejiang 314400 People's Republic of China. 'Livestock and Poultry Research Centre, College of Basic and Applied Sciences, University of Ghana, Legon, P. O Box LG 38, Accra, Ghana. ${ }^{3}$ Department of Animal Biology \& Conservation Science, College of Basic and Applied Sciences, University of Ghana, Legon, Accra, Ghana. ${ }^{4}$ School of Biomedical Sciences, Edinburgh Medical School, College of Medicine \& Veterinary Medicine, The University of Edinburgh, 1 George Square, Edinburgh EH8 9JZ, UK.

Received: 18 October 2021 Accepted: 31 January 2022

Published online: 07 February 2022

\section{References}

1. Zuckerman AJ. Hepatitis viruses. e LS. 2001

2. Modiyinji AF, Atsama MA, Monamele GC, Nola M, Njouom R. High seroprevalence of hepatitis $E$ among pigs suggests an animal reservoir in Cameroon. J Infect Devel Countr. 2018;12(08):676-9.

3. Wen G-P, Tang Z-M, Yang F, Zhang K, Ji W-F, Cai W, et al. A valuable antigen detection method for diagnosis of acute hepatitis E. J Clin Microbiol. 2015:53(3):782-8.

4. Azman AS, Ciglenecki I, Wamala JF, Lynch J, Aggarwal R, Rahman M, et al. Hepatitis E should be considered a neglected tropical disease. PLoS Negl Trop Dis. 2019;13:7.

5. Bagulo H, Majekodunmi AO, Welburn SC. Hepatitis E in sub Saharan Africa-A significant emerging disease. One Health. 2020;1:100186.

6. Supply WUJW, Programme SM, Organization WH. Progress on sanitation and drinking water: 2015 update and MDG assessment: World Health Organization; 2015

7. Dongzagla $\mathrm{A}$, Jewitt $\mathrm{S}, \mathrm{O}^{\prime} \mathrm{H}$ ara $\mathrm{S}$. Seasonality in faecal contamination of drinking water sources in the Jirapa and Kassena-Nankana Municipalities of Ghana. Sci Total Environ. 2021:752:141846.

8. Adjei A, Aviyase J, Tettey Y, Adu-Gyamfi C, Mingle J, Ayeh-Kumi P, et al. Hepatitis E virus infection among pig handlers in Accra, Ghana. East Afr Med J. 2009;86:8

9. Yeboah R, Sylverken AA, Owusu M, El-Duah P, Burimuah V, Frimpong Y, et al. Sero-molecular epidemiology of hepatitis $E$ virus in pigs and human contacts in Ghana. One Health Outlook. 2021;3(1):1-11.

10. Adjei AA, Tettey Y, Aviyase JT, Adu-Gyamfi C, Mingle JA, Nartey ET. Unexpected elevated alanine aminotransferase, aspartate aminotransferase levels and hepatitis E virus infection among persons who work with pigs in accra Ghana. Virol J. 2010;7:336.

11. Tettey Y, Adjei A, Ayivase J, Adu-Gyamfi C, Mingle J, Nartey E, et al. Serological evidence of hepatitis $E$ virus infection among volunteer blood donors at the Accra area blood transfusion center Accra. Ghana J Ghana Sci Assoc. 2011;13(2):64-73.

12. Meldal BH, Sarkodie F, Owusu-Ofori S, Allain JP. Hepatitis E virus infection in Ghanaian blood donors - the importance of immunoassay selection and confirmation. Vox Sang. 2013;104(1):30-6.

13. Adjei AA, Tettey Y, Aviyase JT, Adu-Gyamfi C, Obed S, Mingle JA, et al. Hepatitis E virus infection is highly prevalent among pregnant women in Accra, Ghana. Virol J. 2009;6(1):108

14. Obiri-Yeboah D, Asante Awuku Y, Adu J, Pappoe F, Obboh E, Nsiah P, et al. Sero-prevalence and risk factors for hepatitis $E$ virus infection among pregnant women in the Cape Coast Metropolis, Ghana. PLoS ONE. 2018;13(1):e0191685.

15. UNICEF. 2018/19 District League Table II with New Perspectives and Modified Methodology: UNICEF; 2019.

16. Majekodunmi $\mathrm{AO}$, Addo $\mathrm{HO}$, Bagulo $\mathrm{H}$, Bimi L. Integrated value-chain and risk assessment of Pig-Related Zoonoses in Ghana. PLoS ONE. 2019;14(11):e0224918.

17. Lange H, Øverbø J, Borgen K, Dudman S, Hoddevik G, Urdahl AM, et al. Hepatitis E in Norway: seroprevalence in humans and swine. Epidemiol Infect. 2017;145(1):181-6.

18. Mansuy J-M, Bendall R, Legrand-Abravanel F, Sauné K, Miédouge M, Ellis $\checkmark$, et al. Hepatitis E virus antibodies in blood donors, France. Emerg Infect Dis. 2011:17(12):2309.
19. Bendall R, Ellis $V$, Ijaz S, Ali R, Dalton $H$. A comparison of two commercially available anti-HEV lgG kits and a re-evaluation of anti-HEV lgG seroprevalence data in developed countries. J Med Virol. 2010:82(5):799-805.

20. Abravanel F, Chapuy-Regaud S, Lhomme S, Miedougé M, Peron J-M, Alric $L$, et al. Performance of HEV assays for diagnosing acute hepatitis E in immunocompromised patients. J Clin Virol. 2013;58(4):624-8.

21. Junaid SA, Agina SE, Abubakar KA. Epidemiology and associated risk factors of hepatitis e virus infection in plateau state, Nigeria. Virology (Auckl). 2014:5:15-26.

22. Lin C-C, Wu J-C, Chang T-T, Chang W-Y, Yu M-L, Tam AW, et al. Diagnostic value of immunoglobulin $\mathrm{G}(\mathrm{lgG})$ and $\lg M$ hepatitis $E$ virus (HEV) tests based on HEV RNA in an area where hepatitis $E$ is not endemic. J Clin Microbiol. 2000;38(11):3915-8.

23. Takahashi M, Nishizawa T, Gotanda Y, Tsuda F, Komatsu F, Kawabata T, et al. High prevalence of antibodies to hepatitis $A$ and $E$ viruses and viremia of hepatitis B, C, and D viruses among apparently healthy populations in Mongolia. Clin Diagn Lab Immunol. 2004;11(2):392-8.

24. Adjei AA, Aviyase JT, Tettey Y, Adu-Gyamfi C, Mingle JA, Ayeh-Kumi PF, et al. Hepatitis E virus infection among pig handlers in Accra. Ghana East Afr Med J. 2009:86(8):359-63.

25. Traore KA, Ouoba JB, Huot N, Rogee S, Dumarest M, Traore AS, et al. Hepatitis $E$ virus exposure is increased in pork butchers from Burkina Faso. Am J Trop Med Hyg. 2015;93(6):1356-9.

26. Temmam S, Besnard L, Andriamandimby SF, Foray C, RasamoelinaAndriamanivo $\mathrm{H}$, Heraud JM, et al. High prevalence of hepatitis $\mathrm{E}$ in humans and pigs and evidence of genotype-3 virus in swine Madagascar. Am J Trop Med Hyg. 2013:88(2):329-38.

27. Vitral CL, da Silva-Nunes M, Pinto MA, de Oliveira JM, Gaspar AMC, Pereira RCC, et al. Hepatitis A and E seroprevalence and associated risk factors: a community-based cross-sectional survey in rural Amazonia. BMC Infect Dis. 2014;14(1):1-9.

28. Mast EE, Polish LB, Favorov MO, Khudyakova NS, Collins C, Tukei PM, et al. Hepatitis E among refugees in Kenya: minimal apparent person-to-person transmission, evidence for age-dependent disease expression, and new serologic assays. Viral hepatitis and liver disease: Springer; 1994. p. 375-8.

29. Goumba Al, Konamna X, Komas NP. Clinical and epidemiological aspects of a hepatitis E outbreak in Bangui Central African Republic. BMC Infect Dis. 2011;11:93

30. Corwin A, Putri M, Winarno J, Lubis I, Suparmanto S, Sumardiati A, et al. Epidemic and sporadic hepatitis E virus transmission in West Kaliman$\tan$ (Borneo), Indonesia. Am J Trop Med Hyg. 1997:57(1):62-5.

31. Buti M, Domínguez À, Plans P, Jardí R, Schaper M, Espuñes J, et al. Community-based seroepidemiological survey of hepatitis $E$ virus infection in Catalonia Spain. Clin Vaccine Immunol. 2006;13(12):1328-32.

32. Kuniholm MH, Purcell RH, McQuillan GM, Engle RE, Wasley A, Nelson KE. Epidemiology of hepatitis E virus in the United States: results from the Third National Health and Nutrition Examination Survey, 1988-1994. J Infect Dis. 2009;200(1):48-56.

33. Faber MS, Wenzel JJ, Jilg W, Thamm M, Höhle M, Stark K. Hepatitis E virus seroprevalence among adults, Germany. Emerg Infect Dis. 2012;18(10):1654

34. Khuroo MS, Kamili S, Dar MY, Moecklii R, Jameel S. Hepatitis E and longterm antibody status. Lancet. 1993;341(8856):1355.

35. Tucker TJ, Kirsch RE, Louw SJ, Isaacs S, Kannemeyer J, Robson SC. Hepatitis E in South Africa: evidence for sporadic spread and increased seroprevalence in rural areas. J Med Virol. 1996;50(2):117-9.

36. Abdel Rahman MM, Massoud AM, Kamel MA, Sabry AH, Ahmed GN. Risk of hepatitis "E" virus infection among some schistosomiasis patients in Egypt. J Egypt Soc Parasitol. 1995;25(1):115-23.

37. Caron M, Kazanji M. Hepatitis E virus is highly prevalent among pregnant women in Gabon, central Africa, with different patterns between rural and urban areas. Virol J. 2008;5:158.

38. Vivek R, Chandy GM, Brown DW, Kang G. Seroprevalence of IgG antibodies to hepatitis $E$ in urban and rural southern India. Trans R Soc Trop Med Hyg. 2010;104(4):307-8.

39. Pavio N, Doceul V, Bagdassarian E, Johne R. Recent knowledge on hepatitis $E$ virus in Suidae reservoirs and transmission routes to human. Vet Res. 2017:48(1):1-14 
40. El-Duah P, Dei D, Binger T, Sylverken A, Wollny R, Tasiame W, et al. Detection and genomic characterization of hepatitis E virus genotype 3 from pigs in Ghana Africa. One Health Outlook. 2020;2(1):1-9.

41. Antia RE, Adekola AA, Jubril AJ, Ohore OG, Emikpe BO. Hepatitis E Virus infection seroprevalence and the associated risk factors in animals raised in Ibadan Nigeria. J Immunoassay Immunochem. 2018;39(5):509-20.

42. De Paula SV, Wiele M, Mbunkah AH, Daniel AM, Kingsley MT, SchmidtChanasit J. Hepatitis E virus genotype 3 strains in domestic pigs Cameroon. Emerg Infect Dis. 2013;19(4):666-8.

43. Kaba M, Colson P, Musongela JP, Tshilolo L, Davoust B. Detection of hepatitis $E$ virus of genotype 3 in a farm pig in Kinshasa (Democratic Republic of the Congo). Infect Genet Evol. 2010;10(1):154-7.

\section{Publisher's Note}

Springer Nature remains neutral with regard to jurisdictional claims in published maps and institutional affiliations.

- fast, convenient online submission

- thorough peer review by experienced researchers in your field

- rapid publication on acceptance

- support for research data, including large and complex data types

- gold Open Access which fosters wider collaboration and increased citations

- maximum visibility for your research: over $100 \mathrm{M}$ website views per year

At BMC, research is always in progress.

Learn more biomedcentral.com/submissions 